\title{
Powerful physics
}

\author{
Although driven by the promise of almost limitless energy, fusion research touches on plenty of \\ gripping, fundamental physics - and the wider scientific community has every reason to be supportive.
}

On the night of Halloween in 1997, the Joint European Torus (JET) in Culham, UK, had a treat in store: a new fusion power record of $P_{\mathrm{FUS}}=16.1 \mathrm{MW}$. The facility's late-shift logbook sheet for that day (pictured) somewhat evokes the joy that anyone present in the machine's control room must have felt. Although a celebrated result in fusion science, the registered output power did not, unfortunately, exceed the $P_{\text {in }}=24.1 \mathrm{MW}$ mark - the amount of heating power put in. It takes a $Q=P_{\mathrm{FuS}} / P_{\text {in }}$ value larger than unity to convince a fusion sceptic.

But it is all too easy - and simply unfair to rate the merits of fusion energy research by $Q$ values alone. Yes, the quest for $Q>1$ has been going on for decades. The success of nuclear fission energy - from A-bomb to power plant in less than 10 years certainly fuelled expectations. But although both the US and the USSR tested H-bombs relatively quickly after the Second World War, controlled net energy production from fusion has yet to be achieved.

ITER, the machine that is bound to smash JET's record - the targets are $500 \mathrm{MW}$ of fusion power and $Q=10-$ is now finally being built in the south of France. The idea of a big, international tokamak reactor appeared on the geopolitical agenda during the Gorbachev-Reagan era, but its scientific roots go further back ${ }^{1}$. Of course, it is frustrating that it has taken so long to get going with ITER, but then again, it is also not surprising: a scientific project of such magnitude requires a huge amount of planning, designing and political support.

Political issues aside, the past decades have seen tremendous progress in our understanding of magnetically confined plasmas. There's perhaps even a silver lining to ITER's delays: its design was regularly updated to reflect the latest know-how gathered from modelling and experiments in other tokamaks all over the world. Meanwhile, advances are being made in inertial-confinement fusion, an alternative approach based on laser heating and compression of fusion fuel. Very recently, for example, inertially confined plasmas with dominant self-heating from the $a$-particles produced in deuterium-tritium reactions have been reported ${ }^{2}$.

The cost of government-sponsored projects such as ITER or the National Ignition Facility

\begin{tabular}{|c|c|c|c|c|c|c|c|c|c|c|c|}
\hline \multicolumn{11}{|c|}{$\begin{array}{l}\text { Session Aims: } \\
\text { 1) Max fusion power } \\
\text { 2) Max Q with power step down }\end{array}$} & 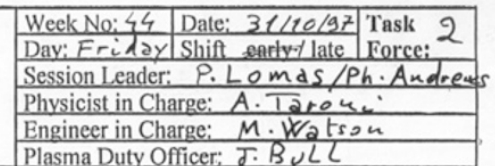 \\
\hline & & & $M A$ & $M x$ & & & & & $M J$ & $M x$ & \multirow[b]{2}{*}{ Comments } \\
\hline \multirow[t]{2}{*}{ Time } & Pulse & $\mathrm{B}_{\mathrm{T}}$ & $\mathrm{I}_{\mathrm{P}}$ & $P_{M \in I}$ & $P_{R F}$ & $\begin{array}{c}T \\
\text { KS } \\
33 \\
\end{array}$ & $\begin{array}{ll}-T+0 \\
K T S P\end{array}$ & $K R 2$ & $V_{D}$ & Prus & \\
\hline & 42973 & & $A B$ & BER & TE & D & & & & & Nea record Fusion Emery $13-3 \mathrm{M}$ \\
\hline 16.12 & $429 \div 4$ & 3.6 & 4.2 & 22.3 & 3 & 0.54 & 0.52 & 0.6 & 16.9 & 15.8 & $0 . k !$ New P Fus Record ! ! \\
\hline 17.19 & 42975 & 3.4 & 3.8 & $\gamma$ & 4 & 1 & 0.48 & 0.6 & 3.7 & C & Tritivm Load shot, RF ouly \\
\hline 18.34 & 42976 & 3.6 & 4.2 & 22.3 & 3 & & 0.5 & 0.6 & 17 & $16 \cdot 1$ & New Records $W_{D}, P_{\text {Fus }}$, Frs. Em $=13.7 \mathrm{M}$ \\
\hline 19.54 & 42972 & 3.4 & 3.8 & 1 & 4 & 0.5 & $\therefore .48$ & 0,6 & 3.8 & C & Cleen up polse, RF ouly \\
\hline 21.3 & 42978 & 3.6 & 4.2 & 16 & 3 & 25 & 0.46 & $0.55^{3}$ & Pag & 538 & Power step down afet socerritule \\
\hline 21.31 & 42979 & 3.6 & 4.2 & 20 & 3 & $\gamma$ & 0.47 & 0.6 & 13.5 & 10.8 & Power step douen not successtul \\
\hline & & & & & WD & & DF & & Ess & $10 \mathrm{~N}$ & sterdown triggered an ELM \\
\hline & & & & & & & & & & & \\
\hline & & & & & & & & & & & \\
\hline & & & & & & & & & & & \\
\hline & & & & & & & & & & & \\
\hline
\end{tabular}

Logbook sheet recording the fusion power record measured at JET, 31 October 1997. The record shot (pulse number 42976) produced a fusion power of 16.1 MW for an input power of 25.3 MW (the sum of radiofrequency and neutral-beam-injection heating power), later re-calibrated to $24.1 \mathrm{MW}$.

in Livermore, US, is, as their critics like to point out, enormous. However, we owe it to future generations to pursue fusion power; we simply cannot afford not to complete these experiments. Moreover, the budgets should be placed in perspective: ITER's estimated cost of about $€ 15$ billion is dwarfed by the $€ 200$ billion that will be spent on hosting the 2022 Football World Cup in Qatar, for example. In addition, there has recently been a steady growth of private-sector interest in less costly (though arguably more speculative) options for achieving fusion.

The goal of net energy production makes it treacherously easy to lose sight of some of the field of nuclear fusion's intrinsic values. The core physics side of fusion research is largely about studying plasmas - the state of matter that is abundantly present in the Universe, not only in laboratories. Astrophysical and laboratory plasmas display similar phenomena; research aiming for a unified understanding of plasmas is of a similarly fundamental level as, say, research on the interface between particle physics and cosmology. Moreover, the analysis of fusion plasmas has required some profound developments in computational and mathematical physics: tackling turbulence has been greatly aided by huge strides in computer power and algorithms, and a Fields Medals was awarded to Cédric Villani in 2010 for his analytical work on Landau damping ${ }^{3}$.

It is clear that nuclear fusion research has a lot to offer to physicists and non-physicists alike. Nature Physics is proud to embrace the field by offering its readers an Insight on the topic. We invite you to turn to page 383 for a selection of articles spanning the breadth and depth of the field, and to join us in marvelling at the rich phenomenology displayed by plasmas - and physicists' and engineers' impressive progress in taming them in pursuit of energy from fusion.

References

1. Clery, D. A Piece of the Sun: The Quest for Fusion Energy (Duckworth, 2013).

2. Hurricane, O. A. et al. Nature Phys. http:dx.doi.org/10.1038/ nphys3720 (2016)

3. Phys. Plasmas 21 (special issue), 030901 (2014). 